\title{
Targeting granzyme B to tumor cells using a yoked human chorionic gonadotropin
}

\author{
Isao Kanatani - Xinjian Lin - Xiaoqin Yuan • \\ Gerald Manorek $\cdot$ Xiying Shang $\cdot$ Lawrence H. Cheung • \\ Michael G. Rosenblum · Stephen B. Howell
}

Received: 19 November 2010/ Accepted: 26 January 2011/Published online: 16 February 2011

(C) The Author(s) 2011. This article is published with open access at Springerlink.com

\begin{abstract}
Purpose Luteinizing hormone receptor (LHR) is found in abundance on human ovarian, breast, endometrial and prostate carcinomas but at only low levels on non-gonadal tissues. To selectively kill LHR-expressing tumors, granzyme B $(\mathrm{GrB})$ was linked to a protein in which both chains of human chorionic gonadotropin were yoked together (YCG). Methods GrB-YCG was expressed and secreted from insect Sf9 cells. Its GrB enzymatic activity and binding affinity for hLHR were then characterized. The differential cytotoxicity of GrB-YCG versus GrB alone was tested in a panel of LHR-expressing tumor cells by SRB assay, and the mechanisms involved in the cell death were investigated by confocal fluorescence microscopy, flow cytometry, and western blot analysis.

Results GrB-YCG was successfully expressed and secreted from Sf9 insect cells and purified from cell culture supernatants. The serine protease activity of GrB-YCG was equivalent to that of human recombinant $\mathrm{GrB}$. An in vitro hormone binding assay revealed that the GrB-YCG
\end{abstract}

I. Kanatani and X. Lin contributed equally to this manuscript.

Electronic supplementary material The online version of this article (doi:10.1007/s00280-011-1573-4) contains supplementary material, which is available to authorized users.

I. Kanatani $\cdot$ X. Lin $\cdot$ X. Yuan · G. Manorek $\cdot$ X. Shang ·

S. B. Howell ( $\square)$

Department of Medicine and the Rebecca and John Moores

UCSD Cancer Center, University of California,

San Diego, La Jolla, CA 92093-0819, USA

e-mail: showell@ucsd.edu

L. H. Cheung · M. G. Rosenblum

Department of Experimental Therapeutics,

University of Texas M. D. Anderson Cancer Center,

Houston, TX, USA molecule also retained the ability to bind to the LHR receptor with an affinity similar to that of native hCG. Upon cell binding, GrB-YCG was rapidly internalized into LHR-expressing human ovarian cancer cells and produced selective and potent tumor cell killing by inducing apoptosis through activation of caspase-3.

Conclusions These results validate LHR as a therapeutic target and indicate that delivery of the human pro-apoptotic enzyme GrB to tumor cells by yoked hCG has substantial selectivity and therapeutic potential for human tumors that express high levels of LHR such as ovarian carcinomas.

Keywords Granzyme B - Human chorionic gonadotropin - Luteinizing hormone receptor . Targeted therapy
Abbreviations
GrB Granzyme B
hCG Human chorionic gonadotropin
LHR Luteinizing hormone receptor
YCG Yoked human chorionic gonadotropin
rEK Recombinant enterokinase

\section{Introduction}

Ovarian cancer remains the most lethal gynecologic malignancy in the United States. Although many patients with advanced-stage disease initially respond to standard combinations of surgical and cytotoxic therapy, nearly $90 \%$ develop recurrence and inevitably die from the development of resistance to cytotoxic chemotherapy [1]. There is an urgent need to develop novel therapeutics that more 
selectively kill ovarian cancer cells. The luteinizing hormone receptor (abbreviated hLHR) is an attractive target for this approach. This receptor specifically binds luteinizing hormone (LH) and human chorionic gonadotropin (hCG) $[2,3]$, which normally have effects only on gonadal tissues where they play an essential role in reproductive function. While the hLHR is expressed at low levels on a variety of other normal tissues [4-6], knockout of LHR in mice does not affect the development of any tissues other than reproductive organs [7]. hLHR is expressed at high levels on ovarian [8-11], prostate [12], breast [13-15], and endometrial $[9,16]$ cancers.

Granzyme B $(\mathrm{GrB})$, a serine-dependent and aspartatespecific protease, is the major effector molecule of cellular immune defense and is released from the granules of activated cytotoxic $\mathrm{T}$ lymphocytes or natural killer cells during their attack on other cells. The mechanism by which $\mathrm{GrB}$ is normally translocated into the cell is not fully understood, although mannose-6-phosphate receptor-mediated endocytosis appears to play some part [17]. Once in the target cell GrB is activated by the removal of two amino acids at the N-terminus; the activated protein then induces apoptosis through either caspase-dependent or independent pathways [18]. Engineering the active form of GrB into an immunotoxin not only confines the delivery of the toxin to the antigen-expressing tumor cells, but also eliminates the need for proteolytic activation once internalized into the target cell. Recently, we have demonstrated that an immunotoxin consisting of GrB linked to a singlechain antibody that targets the gp240 antigen $(\mathrm{GrB} / \mathrm{scFv}$ MEL) was highly cytotoxic to melanoma cells in vitro and was effective in producing a fourfold reduction in the growth of human melanoma A375 xenografts [19]. Other successful immunotoxins developed using human $\mathrm{GrB}$ have included GrB/TGF $\alpha$ and $\mathrm{GrB} /$ anti-ErbB2 scFv that selectively kill tumor cells expressing EGFR or ErbB2 [20], and $\mathrm{GrB} / \mathrm{VEGF}_{121}$ that targets endothelial cells involved in tumor angiogenesis [21].

Although several monoclonal antibodies to hLHR have been reported [22, 23], there are currently no therapeutic antibodies that are sufficiently specific to be used to direct drugs to this target. However, extensive pre-clinical studies have been completed using a peptide derived from the $\beta$-chain of hCG to direct lytic peptides to breast and prostate cancers that express hLHR (reviewed in [24, 25]). The studies demonstrated that such fusion toxins could produce responses in mice carrying human tumor xenografts, and one of these molecules was selected for further development through the RAID program at the NCI. The in vivo response to these toxins was reported to be directly related to LHR density on the tumor cells [15, 25, 26]. Two groups have made attempts to use hCG itself to target either a membrane-disrupting lytic peptide [27] or ribosomal inactivating plant toxin gelonin [28] to this receptor. However, because these molecules were immunogenic, relatively impotent, and displayed very short halflives in the systemic circulation, neither molecule moved forward into clinical development. Thus, we developed a novel type of fusion toxin in which the $\alpha$ - and $\beta$-chains of hCG are linked together to form a single protein ("yoked" hCG, YCG) that is then fused to human granzyme B (GrB). This protein molecule is designed to contain the tumor-targeting moiety YCG that binds hLHR, and the toxin GrB that is a potent apoptotic inducer capable of killing the hLHRoverexpressing cancer cells. Here, we report that GrB-YCG displays potent and selective cytotoxicity toward tumor cells expressing the target $\mathrm{LH}$ receptors.

\section{Materials and methods}

\section{Reagents}

Tissue culture media were purchased from Life Technologies (Frederick, MD) and Thermo Fischer Scientific (Waltham, MA). Bac-to-Bac ${ }^{\circledR}$ Baculovirus Expression system with TOP10 and DH10Bac competent cells, and Sf9 insect cell lines were purchased from Invitrogen (Carlsbad, USA). The BacPak baculovirus titration kit was obtained from Clontech (Mountain View, CA), and metal affinity resin Ni-NTA agarose from Qiagen (Valencia, CA). Rabbit antiHis polyclonal antibody, mouse anti-human granzyme B monoclonal antibody, and rabbit polyclonal anti-LHR antibody were purchased from Santa Cruz Biotechnology, Inc. (Santa Cruz, CA). Rabbit polyclonal antibody against active + pro Caspase 3 was purchased from Abcam, Inc. (Cambridge, MA). Horseradish peroxisome (HRP) or Texas red-labeled secondary antibodies against mouse or rabbit immunoglobulin were obtained from Jackson ImmunoResearch Laboratories, Inc. (West Grove, PA). Human recombinant granzyme $\mathrm{B}$ and $\mathrm{N}-\alpha$-t-butoxycarbonyl-L-alanyl-L-alanyl-L-aspartyl-thiobenzyl ester (BAADT) were purchased from Alexis Biochemicals (San Diego, CA) and 5-,5'-dithiobis (2-nitro benzoic acid) (DTNB, Ellman's reagent) from Thermo Scientific. A native hCG was purchased from Sigma-Aldrich (Saint Louis, MO), and ${ }^{125} \mathrm{I}-\mathrm{hCG}$ was obtained from PerkinElmer Life Sciences (Boston, MA).

\section{Cell lines and cell culture}

The fall armyworm ovarian Sf9 cell line was maintained at $27^{\circ} \mathrm{C}$ in HyClone SFX-INSECT medium supplemented with 5\% fetal bovine serum (FBS, Sigma-Aldrich, St. Louis, MO), $100 \mathrm{U} / \mathrm{ml}$ penicillin, $100 \mathrm{mg} / \mathrm{ml}$ 
streptomycin, and $25 \mu \mathrm{g} / \mathrm{ml}$ amphotericin B. The mouse Leydig tumor cell line MA-10 expressing high levels of LH receptor [29] was grown in RPMI 1640 (Gibco, Grand Island, NY, USA) supplemented with $10 \%$ FBS, $4.5 \mathrm{~g} / 1$ glucose, $2 \mathrm{mM}$ L-glutamine, $100 \mathrm{U} / \mathrm{ml}$ penicillin, $100 \mathrm{mg} / \mathrm{ml}$ streptomycin, $10 \mathrm{mM}$ HEPES (N-2-hydroxyethylpiperazine, $\mathrm{N}$-2-ethanesulfonic acid), 2.2 M sodium pyruvate, and $1.5 \mathrm{~g} / 1$ sodium bicarbonate (all from Invitrogen, Carlsbad, CA), and cultures were maintained at $37^{\circ} \mathrm{C}$ in a humidified atmosphere of $5 \% \mathrm{CO}_{2}$ and $95 \%$ air. The human ovarian carcinoma cell lines 2008 and CA-OV3 were grown in RPMI 1640 supplemented with 5\% fetal bovine serum.

Vector construction and virus preparation

A GrB-YCG fusion DNA construct was generated by an overlapping PCR method. The human mature GrB gene was amplified from the plasmid GrB-scFvMEL [30] by PCR using the forward primer GrB-YCG-50 (5'-T CTT ACA TCT ATG CCG ATC ACC ATC ATC ATC ATC ATG ACG ACG ACG ACA AGA TCA TCG GGG GAC-3') and the reverse primer GrB-YCG-4 (5'-GGA GCC ACC GCC ACC GTA GCG TTT CAT GGT-3' ${ }^{\prime}$ ). The resulting PCR fragment was further extended at its $5^{\prime}$ end in a second PCR using the primers GrB-YCG-48 (5'-C ACC ATG AAA TTC TTA GTC AAC GTT GCC CTTGTT TTT ATG GTC GTA TAC ATT TCT TAC ATC TAT GCC-3') and GrB-YCG-4. The two-step PCR generated the fragment containing BamHI restriction site, the 30-amino acid honey bee melittin (HBM) secretion signal, a six-histidine tag, and an enterokinase (EK) cleavage site. The YCG gene was amplified from plasmid yoked hCG-pVL1393 [31] by PCR using the primers GrBYCG-5 (5'-GG TGG CGG TGG CTC CTC CAA GGA GCC GCT TCG-3') and GrB-YCG-51 (5'-CT ATT AAG ATT TGT GAT AAT AAC AAG TAC TGC-3'). The fused GrBYCG genes were linked together by using primers GrBYCG-48 and GrB-YCG-5. The final GrB-YCG gene product from the splice overlap extension PCR (SOE-PCR) was purified and cloned into the pFastBac1 vector at BamHI and XhoI. The resulting plasmid pFastBac-GrB-YCG was sequence-verified and used to prepare recombinant bacmids by transposition in DH10Bac competent cells. Isolated recombinant bacmid DNA was transfected into $\mathrm{Sf} 9$ cells to produce the recombinant baculovirus coding for GrB-YCG according to the manufacturer's instructions for the Bac-toBac Baculovirus Expression system (Invitrogen). The virus was amplified to generate a stock with viral titers of greater than $1 \times 10^{8}$ plaque-forming units $/ \mathrm{ml}$, as determined with the BacPak baculovirus titration kit (Clontech), and used for protein production.
Large-scale expression and purification of GrB-YCG fusion protein

Large-scale expression was performed using Sf9 cells grown in 2.81 plastic shaker flasks $(900 \mathrm{ml}$ of culture per flask) in serum-free HyQ SFX-Insect medium at $27^{\circ} \mathrm{C}$ and shaking speed of $100 \mathrm{rpm}$. Cells were infected at an MOI of 1 at a cell density of $1.0 \times 10^{6} / \mathrm{ml}$. Cells were harvested $96 \mathrm{~h}$ after infection. All steps hereafter were performed at $4{ }^{\circ} \mathrm{C}$ except where otherwise noted. First, cells and cellular debris were removed by centrifugation for $20 \mathrm{~min}$ at $3,000 \mathrm{~g}$. The supernatant was concentrated to one-thirtieth of its initial volume by using Sartorius $10 \mathrm{kDa}$ cut-off Hydrosart Microfilter Cassette (Goettingen, Germany). The concentrated medium that contained the soluble fraction of the recombinant protein was loaded onto a Ni-NTA column. After washing the column 4 times with a wash buffer (50 $\mathrm{mM} \mathrm{NaH} \mathrm{PO}_{4}, 300 \mathrm{mM} \mathrm{NaCl}$, and $20 \mathrm{mM}$ imidazole, $\mathrm{pH}$ 8.0), the bound proteins were eluted with an elution buffer containing $50 \mathrm{mM} \mathrm{NaH} \mathrm{PO}_{4}, 300 \mathrm{mM} \mathrm{NaCl}$, and $250 \mathrm{mM}$ imidazole ( $\mathrm{pH}$ 8.0). The buffer of the eluate was exchanged by a PD-10 column (GE Healthcare, Piscataway, $\mathrm{NJ}$ ) to $20 \mathrm{mM}$ Tris- $\mathrm{HCl}(\mathrm{pH} \mathrm{7.4)}$ and $50 \mathrm{mM} \mathrm{NaCl}$. The fusion protein was incubated with rEK (Novagen, Madison, WI) to remove the 6xHis tag. rEK was removed using EKapture Agarose according to manufacturer's instructions. The mixture without rEK was further applied to a Ni-NTA column to remove incompletely digested material, the cleaved N-terminal part of the protein containing the $6 \times$ His tag as well as other contaminating proteins. The final protein product was collected in the wash buffer and buffer-exchanged with PBS using a PD-10 column.

Serine protease activity bioassay

The enzymatic activity of the GrB component was determined using a continuous colorimetric assay that utilized $\mathrm{N}$ - $\alpha$ - $t$-butoxycarbonyl-L-alanyl-L-alanyl-L-aspartyl-thiobenzyl ester (BAADT) as a specific substrate for the serine protease activity of $\mathrm{GrB}$ [30]. Assays were performed in a total volume of $100 \mu \mathrm{l}$ and consisted of either recombinant human GrB, GrB-YCG fusion protein before and after cleavage by $\mathrm{EK}$, or EK (control) in buffer A $(0.2 \mathrm{M}$ HEPES, $0.2 \mathrm{M} \mathrm{NaCl}, 1 \mathrm{mM}$ EDTA, $0.05 \%$ (v/v) Triton $\mathrm{X}$-100, pH 7.0), $0.3 \mathrm{mM}$ 5,5'-dithiobis-2-nitrobenzoic acid, and $0.2 \mathrm{mM}$ substrate BAADT at $25^{\circ} \mathrm{C}$. The change in absorbance at $A_{405 \mathrm{~nm}}$ was measured on a Versamax microplate reader (Molecular Devices, Sunnyvale, CA). Increases in sample absorbance were converted to enzymatic rates by using an extinction coefficient of $13,100 \mathrm{~cm}^{-1} \mathrm{M}^{-1}$ at $405 \mathrm{~nm}$. The specific activity (SA) of 
GrB-YCG was calculated using native GrB (Enzyme Systems Products, Livermore, CA) as the standard.

Knockdown of LH receptor expression in Leydig cells using shRNAi lentivirus MISSION ${ }^{\mathrm{TM}}$

Lentiviral Transduction Particles for knockdown of LHR expression were purchased from Sigma (www.sigmaaldrich.com/missionsearch). Briefly, a culture containing 70-80\% confluent Leydig cells was transduced with shRNAi lentiviral constructs at various MOIs for $24 \mathrm{~h}$. The media containing lentiviral particles was then replaced with fresh media, and after a subsequent $24 \mathrm{~h}$ successfully transduced cells were selected by exposure to $10 \mu \mathrm{g} / \mathrm{ml}$ puromycin. The puromycin-containing media was refreshed every 3-4 days until resistant colonies were identified. A minimum of 5 puromycin-resistant clones was picked and expanded into individual cell lines and assayed for knockdown of LHR by a quantitative RT-PCR as described below and by Western blot analysis.

\section{Quantitation of LHR mRNA by real-time PCR}

Total RNA was extracted with TRIzol ${ }^{\circledR}$ reagent (Invitrogen). First-strand cDNA was synthesized using SuperScript II reverse transcriptase (Invitrogen) and random primers. Real-time PCR was done using the Bio-Rad iCycler iQ detection system in the presence of SYBR Green I dye (Bio-Rad Laboratories, Inc., Hercules, CA). For the LHR gene expression, the forward ( $5^{\prime}$-CGC TTT CCA AGG GAT GAA TA- $3^{\prime}$ ) and reverse ( $5^{\prime}$-CAT TGA ATG CAT GGC TTT GT-3') primers were used for amplification with a iCycler protocol consisting of a denaturation program $\left(95^{\circ} \mathrm{C}\right.$ for $3 \mathrm{~min}$ ), amplification and quantification program repeated 40 times $\left(95^{\circ} \mathrm{C}\right.$ for $10 \mathrm{~s}$ and $55^{\circ} \mathrm{C}$ for $45 \mathrm{~s}$ ), and melting curve analysis. The data were analyzed by using the comparative $\mathrm{Ct}$ method, where $\mathrm{Ct}$ is the cycle number at which fluorescence first exceeds the threshold. The $\mathrm{Ct}$ values from each cell line were obtained by subtracting the values for $\beta$-actin $\mathrm{Ct}$ from the sample Ct. A 1-unit difference of $\mathrm{Ct}$ value represents a twofold difference in the level of mRNA.

Analysis of binding of GrB-YCG to LHR

by competitive binding assay

The specificity of the binding of GrB-YCG to LHR was determined using a competitive binding assay. Briefly, cells were plated at a density of $2.0 \times 10^{5}$ cells/well in 24-well plates and allowed to adhere overnight. The cells were then exposed to $200 \mathrm{pM}$ of ${ }^{125} \mathrm{I}-\mathrm{hCG}$ in Waymouth medium containing $0.1 \%$ FBS in the presence of increasing concentrations of unlabeled hCG or GrB-YCG for $6 \mathrm{~h}$.
The final total volume of the reaction mixture was $500 \mu \mathrm{l}$. After washing with PBS 3 times, cells were lysed in $500 \mu \mathrm{l}$ of $1 \mathrm{~N} \mathrm{NaOH}$ and counted in a $\gamma$-counter. An estimate of nonspecific counts was determined in the presence of $1 \mu \mathrm{g} /$ $\mathrm{ml}$ hCG by adding $20 \mu \mathrm{l}$ of $25 \mu \mathrm{g} / \mathrm{ml}$ hCG stock into $480 \mu \mathrm{l}$ cell culture containing $200 \mathrm{pM}$ of ${ }^{125} \mathrm{I}$-hCG. The specific binding after subtracting the nonspecific counts in the absence of competitor was normalized to $100 \%$. The competition curves were plotted as a percentage of the specific binding vs. increasing concentrations of hCG or GrB-YCG on a log scale. The data were fitted to a sigmoidal equation to calculate $\mathrm{IC}_{50}$ values using the Prism software (GraphPad Software, Inc., San Diego, CA).

Internalization and intracellular distribution of $\mathrm{GrB}$ and GrB-YCG detected by immunofluorescent staining

Cells were plated onto polylysine-coated 8 -well chamber slides at $10^{5}$ cells/well and incubated at $37^{\circ} \mathrm{C}$ overnight in $5 \% \mathrm{CO}_{2}$ and air. Cells were treated with $50 \mathrm{nM} \mathrm{GrB}$ or GrB-YCG at $37^{\circ} \mathrm{C}$ for 1,3 and $6 \mathrm{~h}$ and then washed with glycine buffer (500 mM NaCl, $0.1 \mathrm{M}$ glycine, $\mathrm{pH} 2.5$ ) for 2 min to remove GrB-YCG from the cell surface, fixed in $3.7 \%$ formaldehyde, permeabilized in PBS containing $0.2 \%$ Triton X-100 and washed with PBS. After nonspecific binding was blocked with $1 \%$ BSA, cells were incubated with primary antibodies at room temperature for $1 \mathrm{~h}$ and then washed 3 times in PBS containing $0.1 \%$ Tween 20 for $10 \mathrm{~min}$ followed by staining with Texas red-coupled secondary antibodies. After 3 final washes with PBS containing $0.1 \%$ Tween 20 , cells were incubated with $0.1 \%$ Hoechst 33342 for $15 \mathrm{~min}$ and mounted in DABCO mounting medium. Microscopic imaging was performed at the University of California San Diego Cancer Center Digital Imaging Shared Resource using a Zeiss LSM510 confocal microscope system (Carl Zeiss, Inc. Thornwood, NY). Images were captured from $0.8-\mu \mathrm{m}$ sections with a $63 \times$ lens and analyzed by SoftWorx software (Applied Precision, Inc).

In vitro cytotoxicity of GrB versus GrB-YCG

The cells to be tested were plated into 96-well plates at a density of 2,000 cells/well and allowed to adhere overnight and then exposed to different concentrations of either recombinant GrB or purified GrB-YCG. The effects of GrB and GrB-YCG on the growth of tumor cells in culture were determined by SRB assay as described previously [32]. Briefly, cells were allowed to grow for $96 \mathrm{~h}$ in the presence of drugs, after which the media were removed, and the protein was precipitated with $50 \%$ trichloroacetic acid and stained using $100 \mu \mathrm{l}$ of $0.4 \%$ sulforhodamine B in $1 \%$ acetic acid at room temperature for $15 \mathrm{~min}$. After washing, 
the absorbance of each well at a wavelength of $515 \mathrm{~nm}$ was recorded using a Versamax microplate reader (Molecular Devices, Sunnyvale, CA). To examine the protective effect of hCG on GrB-YCG cytotoxicity, the MA-10 cells were treated with the indicated concentrations of hCG for $1 \mathrm{~h}$, washed twice, and challenged with $250 \mathrm{nM}$ GrB-YCG for $96 \mathrm{~h}$. Cell viability was determined by the SRB assay as described above. All experiments were repeated at least 3 times using 3 cultures for each drug concentration.

Flow cytometric analysis of cell death and caspase- 3 cleavage assay

For determining phase distribution of DNA content within the cells treated with $50 \mathrm{nM}$ GrB-YCG for 24, 48, and $72 \mathrm{~h}$, propidium iodide (PI) staining was performed. Briefly, $2 \times 10^{6}$ cells collected were washed once and fixed in $70 \%$ ethanol for $24 \mathrm{~h}$. After centrifugation at $400 \mathrm{~g}$ for $10 \mathrm{~min}$ at $4{ }^{\circ} \mathrm{C}$, cell pellet was stained with $50 \mu \mathrm{g} / \mathrm{ml}$ PI (Sigma, St. Louis, MO) plus $0.5 \mathrm{mg} / \mathrm{ml}$ RNaseA in PBS buffer for $15 \mathrm{~min}$ at room temperature in the dark. Analysis was performed with FACScan flow cytometer (BectonDickinson, Mansfield, MA). The analysis of cell percentage in the sub- $\mathrm{G}_{1}$ phase of cell cycle was performed using the CellQuest software. For detection of caspase- 3 cleavage, the cells were exposed to $50 \mathrm{nM} \mathrm{GrB-YCG}$ for various times $(0,24$ and $48 \mathrm{~h})$, and the cell lysate was analyzed by 4-15\% SDS-PAGE and immunoblotting using a rabbit polyclonal anti-caspase-3 antibody (Abcam, Cambridge, MA) recognizing both a proform and active/cleaved forms of caspase-3.

\section{Results}

Expression, purification, and identification of GrB-YCG fusion protein

We constructed a hormonotoxin in which GrB was fused at its C-terminal end via a flexible linker to YCG (Fig. 1a). This protein was secreted into the culture medium via the honey bee melittin signal sequence and purified by (a)

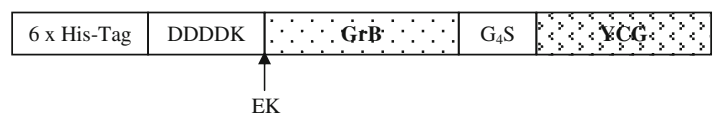

(b)

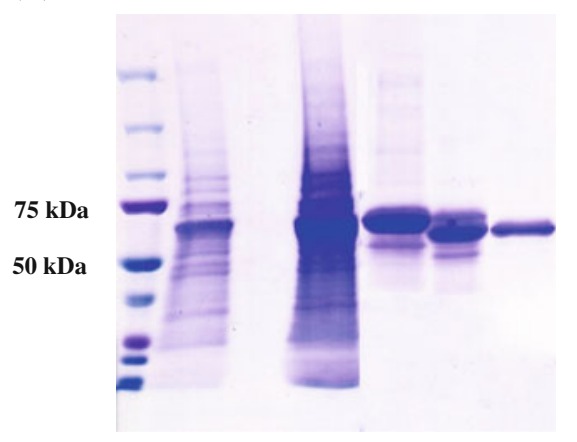

(c)

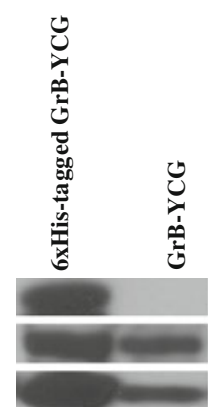

(d)

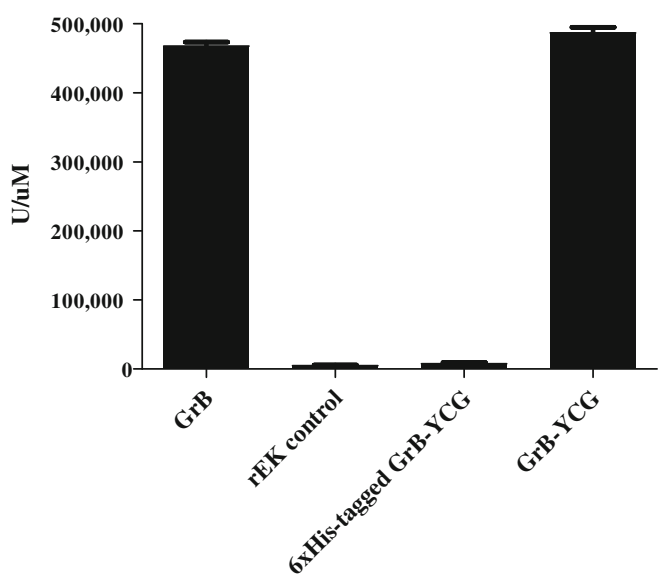

Fig. 1 a Schematic of the structure of hexahistidine-tagged GrBYCG. b Commassie blue-stained SDS-PAGE gel run under reducing conditions showing steps in GrB-YCG purification. The gel shows analysis of medium from infected Sf9 cells, and the subsequent steps in purification. Lane 1 protein markers; lane 2 medium from infected Sf9 cells; lane 3 ultrafiltrate from $10 \mathrm{kDa}$ cut-off Hydrosart Microfilter Cassette when concentrating the harvested medium; lane 4

concentrated medium; lane 5 6xHis-tagged GrB-YCG after purification by nickel-NTA metal affinity chromatography; lane 6 rEKcleaved mixture; lane 7 final purified GrB-YCG. c Western blot analysis of the purified GrB-YCG fusion protein before and after rEK cleavage. d Enzymatic activity of GrB-YCG. The GrB-YCG displayed intact serine protease activity at the same level as human recombinant GrB only after the cleavage by rEK 
nickel-NTA immobilized metal affinity chromatography (IMAC) to 80-90\% purity as assessed by SDS-PAGE (Fig. 1b). Yields were found to be $1-2 \mathrm{mg}$ of purified protein per liter of culture. The protein migrated with an apparent molecular mass significantly higher than the $53.3 \mathrm{kDa}$ calculated from the amino acid sequence. This was likely due to glycosylation that occurred when the protein was produced in Sf9 cells. The hexahistidine tag was removed by cleavage with recombinant enterokinase ( $\mathrm{rEK}$ ) resulting in the final GrB-YCG product with no other contaminating bands as shown in Lane 7 of Fig. 1b. The identity of the cleaved fusion protein was confirmed by Western blot analysis of the uncleaved and rEK-cleaved protein using anti-his, anti-GrB, and anti-hCG antibodies. As shown in Fig. 1c the cleaved protein was detected by both anti-GrB and anti-hCG antibodies but not by anti-his antibody indicating that the hexahistidine tag had been successfully removed. To assess the biological activity of the GrB component of the fusion construct, the ability of the enzyme to cleave a BAADT substrate was assessed and compared with the activity of native recombinant GrB. Figure 1d showed that neither rEK nor GrB-YCG containing the hexahistidine tag were able to hydrolyze the BAADT substrate, whereas removal of the hexahistidine tag resulted in activity comparable to that of recombinant native $\mathrm{GrB}$.

Generation and characterization of LHR knockdown cells

To establish a biological system for testing the potency and selectivity of the GrB-YCG toxin, we performed a shRNAi-mediated constitutive knockdown of LHR expression in the transformed murine Leydig cell line MA-10 using shRNAi lentivirus. LHR-positive MA-10 cells were infected with mouse LHR shRNAi-expressing lentivirus.
Individual puromycin-resistant clones were expanded, and the resulting populations were screened for LHR mRNA expression by RT-PCR. The population with the greatest percent reduction in LHR was designated MA10-LHRKD5.3. As shown in Fig. 2a, the LHR mRNA levels in the clone MA10-LHRKD-5.3 were reduced to $10.9 \%$ of that in the parental MA-10 cells. The decreased expression of mLHR mRNA was accompanied by a $93 \%$ reduction in the capacity of the cells to bind ${ }^{125} \mathrm{I}-\mathrm{hCG}$ (Fig. 2b). LHR receptor number was determined by a competitive binding assay as reported previously [33] in which the hCG was used as both radioligand and competitor. This revealed that the MA10-LHRKD-5.3 cells expressed only $3.85 \times 10^{4}$ LHR/cell, whereas there were $\sim 1.22 \times 10^{6} \mathrm{LHR} /$ cell on the parental MA-10 cells; a 97\% reduction in LHR levels on the cell surface.

Binding of GrB-YCG to LHR on tumor cells

The ability of YCG component of GrB-YCG to bind to the LHR was determined by competitive binding assay. MA10 cells were incubated with ${ }^{125} \mathrm{I}-\mathrm{hCG}$ and increasing concentrations of native hCG or GrB-YCG. The displacement curves (Fig. 3) indicate that the affinities of the standard urinary $\mathrm{hCG}$ and $\mathrm{GrB}-\mathrm{YCG}$ for the $\mathrm{LH}$ receptor were only twofold different with $\mathrm{IC}_{50}$ values of 70.6 and $132.4 \mathrm{nM}$, respectively.

Internalization of GrB-YCG into LHR-expressing tumor cells

The ability of YCG to cause the internalization of the linked GrB component was assessed by exposing the parental MA-10 and the LHR-knockdown MA10LHRKD-5.3 cells to $50 \mathrm{nM}$ of either recombinant $\mathrm{GrB}$ or GrB-YCG for $3 \mathrm{~h}$ and determining the amount of
Fig. 2 Generation and characterization of clones of Leydig tumor cells in which LHR expression had been knocked down. a Relative LHR mRNA levels in the parental MA-10 and MA10-LHRKD-5.3 subline. b Relative binding of

${ }^{125}$ I-hCG to LHR on the MA-10 and MA10-LHRKD-5.3 cells (a)

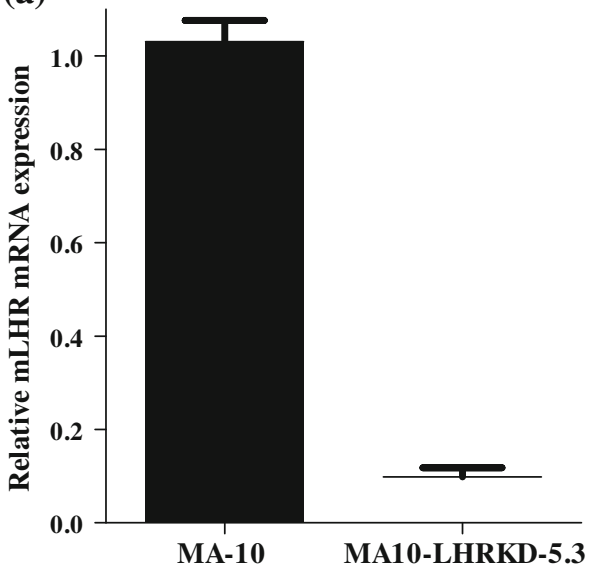

(b)

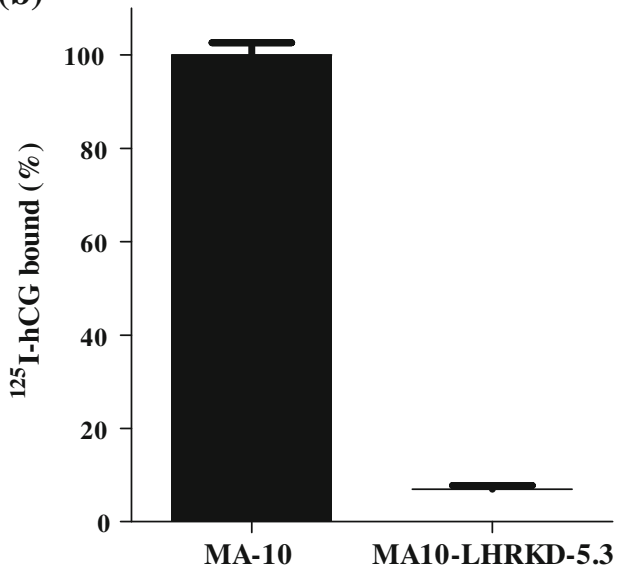




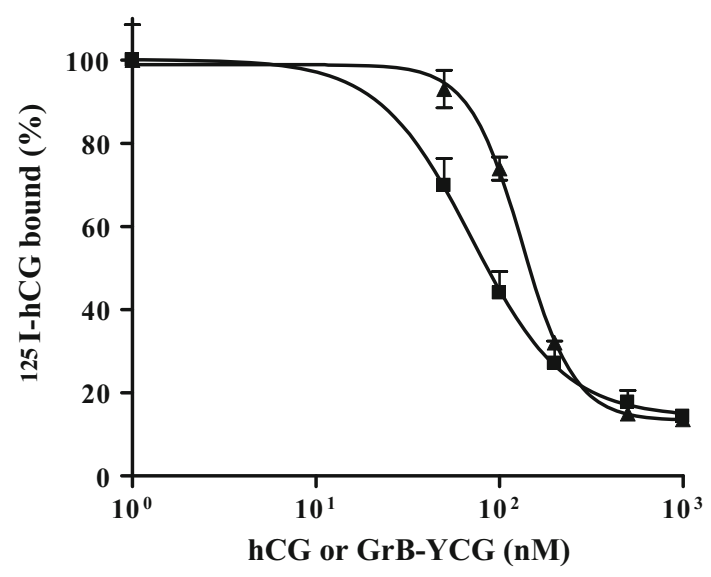

Fig. 3 Competitive binding assay with GrB-YCG. Leydig tumor cells were treated with $200 \mathrm{pM}$ of ${ }^{125} \mathrm{I}-\mathrm{hCG}$ and increasing concentrations of native hCG (filled square) or GrB-YCG (filled triangle) for $6 \mathrm{~h}$. The specific binding of ${ }^{125} \mathrm{I}-\mathrm{hCG}$ in the absence of competitor is normalized to $100 \%$. Each data point represents the mean \pm SEM of 3 independent experiments intracellular GrB using an antibody specific for $\mathrm{GrB}$ and quantitative analysis of confocal images. As shown in Fig. 4, we found no significant GrB staining following exposure of either type of cell to recombinant GrB. However, GrB-YCG was shown to be extensively internalized into the parental MA-10 cells (Fig. 4c). This internalization was eliminated by the knockdown of LHR because minimal staining was observed in the MA10LHRKD-5.3 cells. In the majority of the treated MA-10 cells, both diffuse and patchy staining was found within the cytoplasm suggesting efficient uptake of GrB-YCG into endosomes and its subsequent release into the cytoplasm. Significant levels of cytosolic GrB-YCG were also found in 2008 and OVCAR-3 ovarian carcinoma cells treated with $250 \mathrm{nM}$ GrB-YCG for $3 \mathrm{~h}$ (data not shown). These results indicate that binding of the YCG component of the GrB-YCG to LHR on the tumor cell surface is responsible for its internalization.
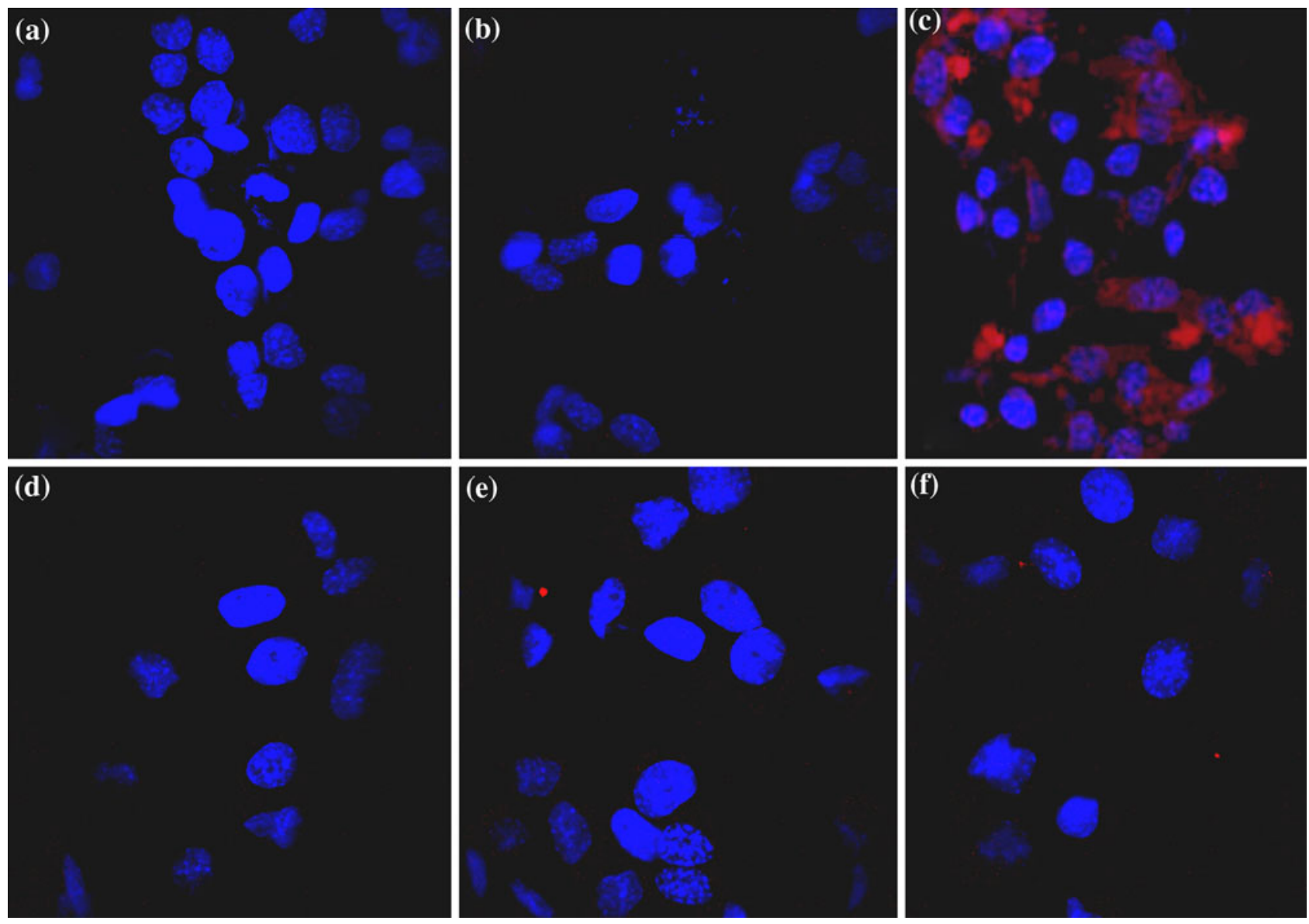

Fig. 4 Internalization of GrB-YCG into the parental MA-10 and MA10-LHRKD-5.3 cells treated with $50 \mathrm{nM} \mathrm{GrB-YCG}$ for $3 \mathrm{~h}$. Cells were permeabilized and stained with mouse anti-GrB and Texas red-conjugated anti-mouse $\operatorname{IgG}$, while nuclei were stained with
Hoechst 33342. a Untreated parental MA-10 cells; b MA-10 cells exposed to recombinant GrB; c MA-10 cells exposed to GrB-YCG; d untreated MA10-LHRKD-5.3 cells; e MA10-LHRKD-5.3 cells exposed to GrB; f MA10-LHRKD-5.3 cells exposed to GrB-YCG 
In vitro cytotoxic effects of GrB-YCG

To examine the potency and selectivity of GrB-YCG, we compared the cytotoxicity of free GrB and GrB-YCG to the MA-10, 2008 and OVCAR-3 cells. Figure 5a shows that whereas free GrB produced no killing of the LHRexpressing MA-10 cells up to a concentration of $1 \mu \mathrm{M}$, GrB-YCG produced a concentration-dependent reduction in viability with an $\mathrm{IC}_{50}$ of $0.16 \mu \mathrm{M}$. In contrast, GrB-YCG was not cytotoxic to MA10-LHRKD-5.3 cells at concentration of up to $1 \mu \mathrm{M}$ (Fig. 1, supplementary material), a concentration that killed $99.9 \%$ of the MA-10 cells. Similar results were obtained with the ovarian cancer cell lines 2008 and OVCAR-3. At the highest concentration tested (1 $\mu \mathrm{M}), \mathrm{GrB}-\mathrm{YCG}$ produced $90 \%$ inhibition of cell growth in the both cell lines, whereas native GrB caused only 35 and $9 \%$ growth inhibition of the LHR-expressing OVCAR3 (Fig. 5b) and 2008 (Fig. 5c) cells, respectively. Interestingly but expectedly, the recombinant fusion construct
GrB-YCG also demonstrated a differential cytotoxicity against LHR-expressing human breast cancer cell line MCF-7 and human prostate cancer cell line PC-3, compared to GrB alone (Fig. 2, supplementary material). To further confirm that the enhanced cytotoxicity of GrB-YCG was dependent on the YCG moiety, MA-10 cells were pretreated with increasing concentrations of free hCG and then exposed to a cytotoxic concentration of GrB-YCG. As shown in Fig. 5d, hCG protected the MA-10 cells in a concentration-dependent manner when they were subsequently challenged with $0.25 \mu \mathrm{M}$ GrB-YCG. These results are consistent with the concept that pre-incubation with hCG protected MA-10 cells by saturating the LH receptors that mediate the cytotoxicity of GrB-YCG.

GrB-YCG-induced apoptosis and caspase-3 cleavage

Changes in DNA integrity are the hallmark of cellular apoptosis. The occurrence of apoptotic cell death was
Fig. 5 Cytotoxic effect of GrB-YCG on the LHRexpressing MA-10 (a), OVCAR-3 (b) and 2008 (c) cells and the protective effect of hCG on the cytotoxicity of GrB-YCG in the MA-10 cells (d). (filled square) $\mathrm{GrB}$; (filled triangle) GrB-YCG. Each data point represents the mean of 3 independent experiments each performed with triplicate cultures. Vertical bars, \pm SEM (a)

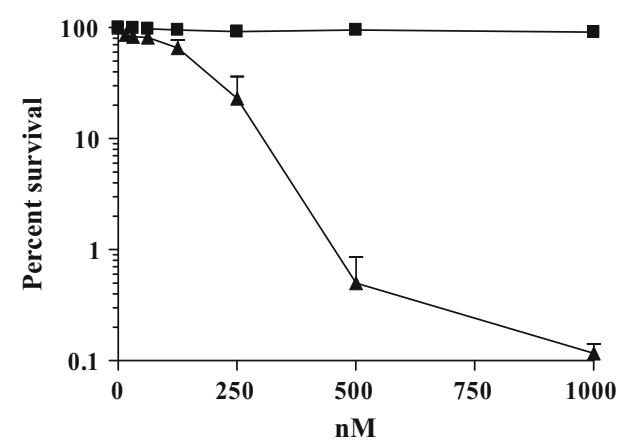

(c)

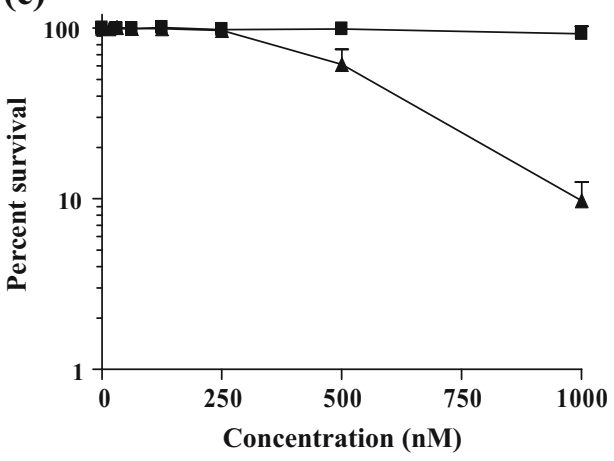

(b)

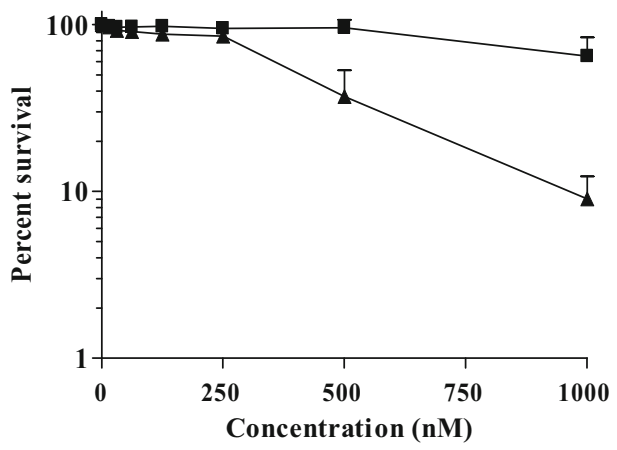

(d)

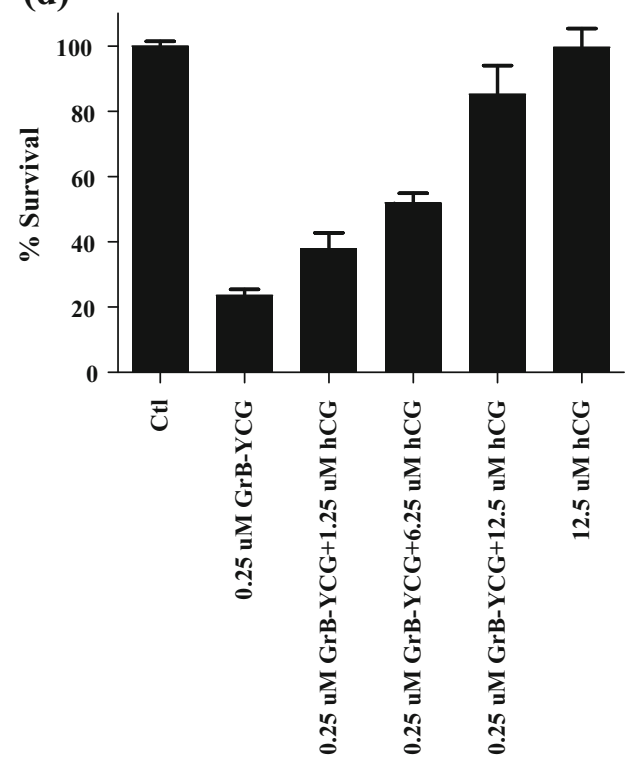


Fig. 6 Apoptosis induction by GrB-YCG in the

LHR-expressing MA-10 cells. a Quantification of sub-G1 peak by flow cytometry.

M1 percentage of apoptotic cells and debris (damaged cells) in the sub- $\mathrm{G}_{0}$ fraction,

$R 3$ represents the apoptotic nuclei with reduced DNA content excluding the debris. b GrB-YCG-induced caspase-3 cleavage in the MA-10 cells
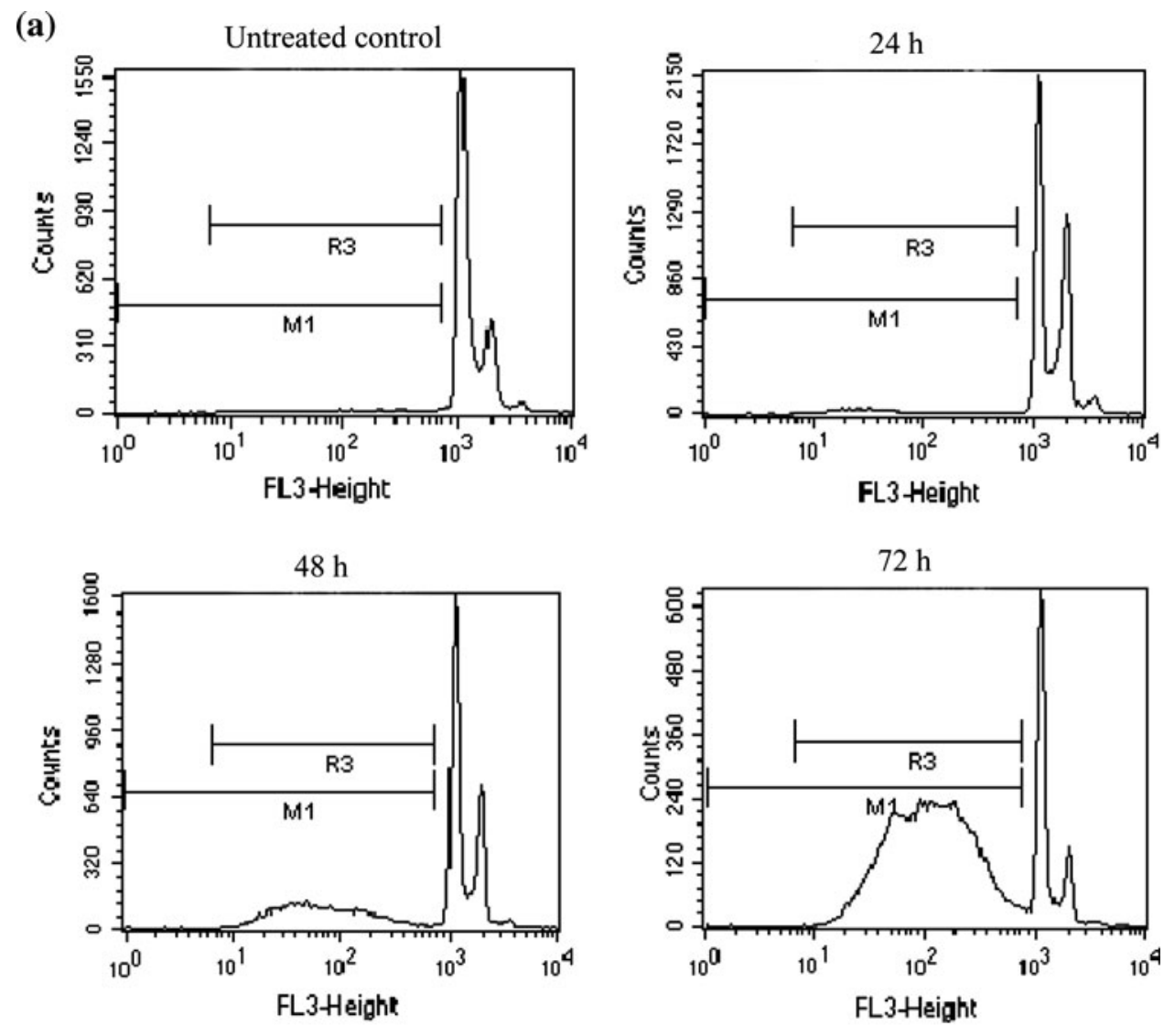

(b)

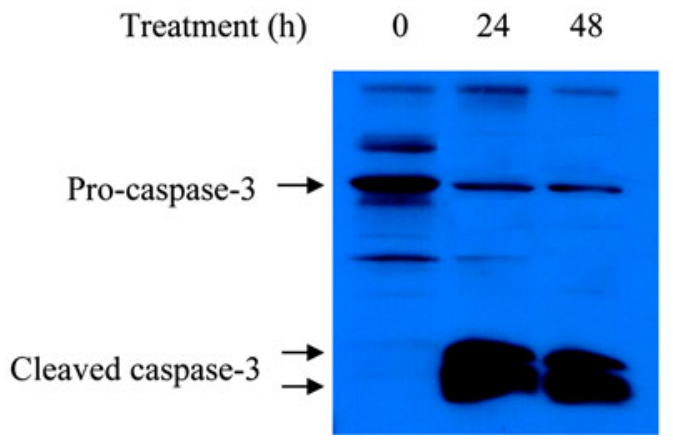

analyzed by flow cytometry after staining of cells with prodium iodide; the fraction of dead cells is represented by the sub- $\mathrm{G}_{1}$ fluorescent peak. As shown in Fig. $6 \mathrm{a}, 24 \mathrm{~h}$ after treatment with $50 \mathrm{nM} \mathrm{GrB-YCG}$, the LHR-expressing MA-10 cells started to show an increase in the percentage of apoptotic cells. The apoptotic fraction of the treated cells increased to 25.3 and $54.8 \%$ at $48 \mathrm{~h}$ and $72 \mathrm{~h}$, respectively. The majority of apoptosis induced by GrB is known to be mediated by caspase- 3 activation, so we next examined the effects of GrB-YCG on the activation of caspase-3. After treatment of the MA-10 cells with the fusion construct for 24 or $48 \mathrm{~h}$, procaspase- 3 was shown to be cleaved into the large $(17 \mathrm{kDa})$ and small $(12 \mathrm{kDa})$ subunits of active/ cleaved caspase-3 (Fig. 6b).

\section{Discussion}

Epithelial tumors of the ovary are highly lethal, but at least $40 \%$ of these tumors express the luteinizing hormone receptor (LHR) at high levels, as do many prostate and breast cancers [34]. Therefore, the LH receptor is of interest with respect to the selective delivery of cytotoxic agents directly into these malignant cells. While efforts have been made to use a 15 -amino acid segment of the beta chain of hCG to target a membrane-disrupting lytic peptide [27] or to use full-length hCG itself to target a ribosomal inactivating plant toxin gelonin [28] to this receptor, these molecules were potentially immunogenic, relatively impotent and have very short half-lives in the systemic 
circulation. In addition, these molecules are chemical conjugates. On the one hand, premature release of cytotoxic agents from such conjugates due to linker degradation can result in nonspecific toxicity; on the other hand, linkers that are too stable can result in failure to release the active agent in a timely manner, thereby compromising the effectiveness of the successfully delivered agent [35]. Two developments support the approach of directly fusing a toxin to hCG rather than utilizing chemical conjugation. First, it has now been shown that the $\beta$ - and $\alpha$-chains of hCG can be connected by a short linker and produced as a single polypeptide chain ("yoked hCG") that retains high affinity and specificity for the LHR [31]. Second, human $\mathrm{GrB}$ has been validated as a highly effective toxin that, when introduced into the interior of the cell through linkage to a targeting moiety, rapidly triggers apoptosis [30]. Such fusion toxins have already been shown to have attractive pharmacokinetic characteristics and to have efficacy in a variety of different tumor models [21, 36]. A single protein containing GrB fused to a targeting moiety is more attractive as a therapeutic than a molecule to which a toxin has been chemically conjugated due to the fact that the former approach eliminates concern about the linker and results in a molecule that is likely less immunogenic and thus compatible with multiple cycles of administration.

We have successfully expressed the GrB-YCG fusion toxin, consisting of the human pro-apoptotic serine protease $\mathrm{GrB}$ and the $\beta$ - and $\alpha$-chains of hCG yoked together, as secreted protein in insect $\mathrm{Sf} 9$ cells with the yields of approximately $1.5 \mathrm{mg}$ per liter of culture medium. This protein was designed to contain a hexahistidine tag and enterokinase cleavage site at the $\mathrm{N}$-terminal end such that the fusion protein could be easily purified by affinity chromatography and active GrB could be released by cleavage with enterokinase. The rEK-cleaved final product was recognized by both anti-GrB and anti-hCG antibodies but not by antibody to the hexahistidine tag consistent with the removal of the N-terminal tag. The GrB-YCG containing the histidine tag, or from which it had been removed, were then tested for their ability to cleave an artificial peptide substrate BocAlaAlaAsp-thiobenzyl ester. The protein from which the tag had been removed, but not that containing the tag, cleaved the synthetic GrB substrate, and its activity was indistinguishable from that of native $\mathrm{GrB}$. The final fusion protein GrB-YCG was bifunctional in that it contained GrB activity and was also capable of binding specifically to MA-10 cells expressing high levels of the LHR receptor. The affinity of the GrB-YCG for LHR was only twofold lower than that of native urinary hCG ( $\mathrm{IC}_{50} 132.4 \mathrm{nM}$ vs. $70.6 \mathrm{nM}$ ), presumably due to differences in glycosylation between the recombinant and native hCG. It is known that baculovirus-expressed glycoprotein does not contain sialic acid because Sf9 cells, while having a glycosylation apparatus capable of synthesizing high mannose type carbohydrates and simple $O$-linked chains [37], lack sialytransferases [31].

Wild-type GrB is able to internalize slowly into target cells, but localizes in vesicular structures inside the cytoplasm where it remains inactive [38]. Induction of apoptosis is only observed after the addition of perforin which is thought to liberate $\mathrm{GrB}$ from these vesicles, allowing assess of the protease to the cytosol. Recent studies have suggested that the mannose-6-phosphate receptor [17] could also mediate GrB entry by receptor-mediated endocytosis [38] and that under these circumstances perforin may act to release endosomal GrB into the cytosol of the target cell [39]. The current study clearly demonstrates that the yoked hCG can mediate the selective cellular accumulation of GrB in cells expressing the LHR. Based on the fact that such uptake is accompanied by cellular cytotoxicity, some fraction of the GrB must gain access to the cytoplasm even in the absence of perforin. Although nonspecific cellular entry of GrB could possibly be mediated by the mannose-6-phosphate receptor, the substantially enhanced cytotoxicity of GrB-YCG compared to unmodified $\mathrm{GrB}$ indicated that YCG is the carrier molecule that delivers the attached $\mathrm{GrB}$ into the cytoplasm of target tumor cells after binding to the cell surface LHR. Consistent with this finding, immunofluorescent staining clearly showed that GrB-YCG was found in much greater abundance than GrB alone in LHR-positive MA-10 cells following a 3-h exposure to equal concentrations, and that GrB staining was minimal in LHR-knockdown cells exposed to either GrB-YCG or GrB only.

An ideal carrier would be a nonimmunogenic molecule binding to a cell surface receptor expressed predominantly in cancer cells. Furthermore, after binding to the cell surface, the fusion toxin should be transferred into the cytoplasm. hCG fulfills most of these criteria since it is nonimmunogenic, has a long plasma half-life, binds avidly to a cell surface LHR, and is transferred into the cell after binding. hCG receptors are expressed at high levels in tissues of the female genital tract, and its malignancies but not in most other tissues. The function of hCG and hCG receptors in gynecologic malignancies is still somewhat unclear. Kuroda et al. [40] studied the biological aspect of LH/hCG action in ovarian cancer using the $\mathrm{LH} / \mathrm{hCG}$ receptor-positive $\mathrm{OV}$ CAR-3 and LHR-negative SK-OV-3 cell lines and showed that treatment with hCG did not affect cell proliferation in either cell line, consistent with our finding that hCG alone even at $12.5 \mu \mathrm{M}$ did not affect the viability of MA-10 cells. It is reasonable to speculate that the increased cytotoxic activity of GrB-YCG is attributable to specific uptake of the molecule due to YCG binding to the LHR not to any additional toxic effect of YCG itself. Furthermore, treatment with a mixture of hCG and $\mathrm{GrB}$ that had not been fused together did not show any enhancement of cell killing over that 
produced by GrB on LHR-positive cell lines (Fig. 3, supplementary material).

Our data demonstrate that GrB-YCG can be readily expressed in Sf9 cells and that, upon specific binding to the LHR on the surface of tumor cells, the fusion molecules are internalized and distributed into the cytosol resulting in efficient cell killing. Since both the GrB and yoked hCG components of GrB-YCG are of human origin, the risk that the molecule will be immunogenic is substantially reduced. Toxins such as gelonin, Pseudomonas exotoxin, or ricin toxin A chain, which are derived from plants or bacteria, are highly immunogenic in humans [41] and tend to induce drug resistance after several treatments [42]. Because GrB activates numerous independent cascade events through enzymatic mechanisms of action, the development of resistance to $\mathrm{GrB}$ is unlikely. GrB-YCG has potential as the first of new class of cancer chemotherapeutic agents for the treatment of ovarian, breast, and prostate carcinomas, as well as other types of tumors that express high levels of the LH receptor.

Acknowledgments The authors would like to thank Dr. David Puett for generously providing the Yoked hCG pVL1393 vector. This work was supported by the Clayton Medical Research Foundation and conducted, in part, by the Clayton Foundation for Research.

Open Access This article is distributed under the terms of the Creative Commons Attribution Noncommercial License which permits any noncommercial use, distribution, and reproduction in any medium, provided the original author(s) and source are credited.

\section{References}

1. Santin AD, Cane S, Bellone S, Palmieri M, Siegel ER, Thomas M, Roman JJ, Burnett A, Cannon MJ, Pecorelli S (2005) Treatment of chemotherapy-resistant human ovarian cancer xenografts in C.B-17/SCID mice by intraperitoneal administration of Clostridium perfringens enterotoxin. Cancer Res 65(10):4334-4342

2. Rajaniemi H, Kauppila A, Ronnberg L, Selander K, Pystynen P (1981) $\mathrm{LH}(\mathrm{hCG})$ receptor in benign and malignant tumors of human ovary. Acta Obstet Gynecol Scand Suppl 101:83-86

3. Mandai M, Konishi I, Kuroda H, Fukumoto M, Komatsu T, Yamamoto S, Nanbu K, Rao CV, Mori T (1997) Messenger ribonucleic acid expression of $\mathrm{LH} / \mathrm{hCG}$ receptor gene in human ovarian carcinomas. Eur J Cancer 33(9):1501-1507

4. Lu JJ, Zheng Y, Kang X, Yuan JM, Lauchlan SC, Pike MC, Zheng W (2000) Decreased luteinizing hormone receptor mRNA expression in human ovarian epithelial cancer. Gynecol Oncol 79(2):158-168

5. Pabon JE, Li X, Lei ZM, Sanfilippo JS, Yussman MA, Rao CV (1996) Novel presence of luteinizing hormone/chorionic gonadotropin receptors in human adrenal glands. J Clin Endocrinol Metab 81(6):2397-2400

6. Licht P, von Wolff M, Berkholz A, Wildt L (2003) Evidence for cycle-dependent expression of full-length human chorionic gonadotropin/luteinizing hormone receptor mRNA in human endometrium and decidua. Fertil Steril 79(Suppl 1):718-723

7. Zhang FP, Poutanen M, Wilbertz J, Huhtaniemi I (2001) Normal prenatal but arrested postnatal sexual development of luteinizing hormone receptor knockout (LuRKO) mice. Mol Endocrinol 15(1):172-183

8. Kammerman S, Demopoulos RI, Raphael C, Ross J (1981) Gonadotropic hormone binding to human ovarian tumors. Hum Pathol 12(10):886-890

9. Konishi I, Koshiyama M, Mandai M, Kuroda H, Yamamoto S, Nanbu K, Komatsu T, Matsushita K, Rao CV, Mori T (1997) Increased expression of $\mathrm{LH} / \mathrm{hCG}$ receptors in endometrial hyperplasia and carcinoma in anovulatory women. Gynecol Oncol 65(2):273-280

10. Reinholz MM, Zschunke MA, Roche PC (2000) Loss of alternately spliced messenger RNA of the luteinizing hormone receptor and stability of the follicle-stimulating hormone receptor messenger RNA in granulosa cell tumors of the human ovary. Gynecol Oncol 79(2):264-271

11. Steinmeyer C, Berkholz A, Gebauer G, Jager W (2003) The expression of hCG receptor mRNA in four human ovarian cancer cell lines varies considerably under different experimental conditions. Tumour Biol 24(1):13-22

12. Tao YX, Bao S, Ackermann DM, Lei ZM, Rao CV (1997) Expression of luteinizing hormone/human chorionic gonadotropin receptor gene in benign prostatic hyperplasia and in prostate carcinoma in humans. Biol Reprod 56(1):67-72

13. Meduri G, Charnaux N, Loosfelt H, Jolivet A, Spyratos F, Brailly S, Milgrom E (1997) Luteinizing hormone/human chorionic gonadotropin receptors in breast cancer. Cancer Res 57(5):857-864

14. Hu YL, Lei ZM, Huang ZH, Rao CV (1999) Determinants of transcription of the chorionic gonadotropin/luteinizing hormone receptor gene in human breast cells. Breast J 5(3):186-193

15. Leuschner C, Enright FM, Gawronska B, Hansel W (2003) Membrane disrupting lytic peptide conjugates destroy hormone dependent and independent breast cancer cells in vitro and in vivo. Breast Cancer Res Treat 78(1):17-27

16. Lin J, Lei ZM, Lojun S, Rao CV, Satyaswaroop PG, Day TG (1994) Increased expression of luteinizing hormone/human chorionic gonadotropin receptor gene in human endometrial carcinomas. J Clin Endocrinol Metab 79(5):1483-1491

17. Motyka B, Korbutt G, Pinkoski MJ, Heibein JA, Caputo A, Hobman M, Barry M, Shostak I, Sawchuk T, Holmes CF, Gauldie J, Bleackley RC (2000) Mannose 6-phosphate/insulin-like growth factor II receptor is a death receptor for granzyme B during cytotoxic T cell-induced apoptosis. Cell 103(3):491-500

18. Wowk ME, Trapani JA (2004) Cytotoxic activity of the lymphocyte toxin granzyme B. Microbes Infect 6(8):752-758

19. Liu Y, Zhang W, Cheung LH, Niu T, Wu Q, Li C, Van Pelt CS, Rosenblum MG (2006) The antimelanoma immunocytokine scFvMEL/TNF shows reduced toxicity and potent antitumor activity against human tumor xenografts. Neoplasia 8(5):384-393

20. Dalken B, Giesubel U, Knauer SK, Wels WS (2006) Targeted induction of apoptosis by chimeric granzyme B fusion proteins carrying antibody and growth factor domains for cell recognition. Cell Death Differ 13(4):576-585

21. Liu Y, Cheung LH, Thorpe P, Rosenblum MG (2003) Mechanistic studies of a novel human fusion toxin composed of vascular endothelial growth factor (VEGF)121 and the serine protease granzyme B: directed apoptotic events in vascular endothelial cells. Mol Cancer Ther 2(10):949-959

22. Bielinska M, Genova E, Boime I, Parviainen H, Kiiveri S, Leppaluoto J, Rahman N, Heikinheimo M, Wilson DB (2005) Gonadotropin-induced adrenocortical neoplasia in NU/J nude mice. Endocrinology 146(9):3975-3984

23. Funaro A, Sapino A, Ferranti B, Horenstein AL, Castellano I, Bagni B, Garotta G, Malavasi F (2003) Functional, structural, and distribution analysis of the chorionic gonadotropin receptor using murine monoclonal antibodies. J Clin Endocrinol Metab 88(11):5537-5546 
24. Hansel W, Leuschner C, Enright F (2007) Conjugates of lytic peptides and LHRH or betaCG target and cause necrosis of prostate cancers and metastases. Mol Cell Endocrinol 269(1-2): 26-33

25. Leuschner C, Hansel W (2005) Targeting breast and prostate cancers through their hormone receptors. Biol Reprod 73:860865

26. Hansel W, Leuschner C, Gawronska B, Enright F (2001) Targeted destruction of prostate cancer cells and xenografts by lytic peptide-betaLH conjugates. Reprod Biol 1(1):20-32

27. Gawronska B, Leuschner C, Enright FM, Hansel W (2002) Effects of a lytic peptide conjugated to beta HCG on ovarian cancer: studies in vitro and in vivo. Gynecol Oncol 85(1): 45-52

28. Singh V, Sairam MR (1989) Hormonotoxins: conjugation of human choriogonadotropin with the ribosome inactivating protein gelonin and comparison with a lutropin conjugate. Mol Cell Endocrinol 67(2-3):217-229

29. Ascoli M (1981) Characterization of several clonal lines of cultured Leydig tumor cells: gonadotropin receptors and steroidogenic responses. Endocrinology 108(1):88-95

30. Liu Y, Cheung LH, Hittelman WN, Rosenblum MG (2003) Targeted delivery of human pro-apoptotic enzymes to tumor cells: in vitro studies describing a novel class of recombinant highly cytotoxic agents. Mol Cancer Ther 2(12):1341-1350

31. Narayan P, Wu C, Puett D (1995) Functional expression of yoked human chorionic gonadotropin in baculovirus-infected insect cells. Mol Endocrinol 9(12):1720-1726

32. Larson CA, Blair BG, Safaei R, Howell SB (2009) The role of the mammalian copper transporter 1 in the cellular accumulation of platinum-based drugs. Mol Pharmacol 75(2):324-330

33. DeBlasi A, O'Reilly K, Motulsky HJ (1989) Calculating receptor number from binding experiments using same compound as radioligand and competitor. Trends Pharmacol Sci 10(6):227-229
34. Ziecik AJ, Kaczmarek MM, Blitek A, Kowalczyk AE, Li X, Rahman NA (2007) Novel biological and possible applicable roles of LH/hCG receptor. Mol Cell Endocrinol 269(1-2):51-60

35. Dosio F, Brusa P, Delprino L, Grosa G, Ceruti M, Cattel L (1994) A new approach in the synthesis of immunotoxins: ribosome inactivating protein noncovalently bound to monoclonal antibody. J Pharm Sci 83(2):206-211

36. Liu Y, Zhang W, Niu T, Cheung LH, Munshi A, Meyn RE Jr, Rosenblum MG (2006) Targeted apoptosis activation with GrB/ scFvMEL modulates melanoma growth, metastatic spread, chemosensitivity, and radiosensitivity. Neoplasia 8(2):125-135

37. Chen W, Bahl OP (1991) Recombinant carbohydrate and selenomethionyl variants of human choriogonadotropin. J Biol Chem 266(13):8192-8197

38. Froelich CJ, Orth K, Turbov J, Seth P, Gottlieb R, Babior B, Shah GM, Bleackley RC, Dixit VM, Hanna W (1996) New paradigm for lymphocyte granule-mediated cytotoxicity. Target cells bind and internalize granzyme $\mathrm{B}$, but an endosomolytic agent is necessary for cytosolic delivery and subsequent apoptosis. J Biol Chem 271(46):29073-29079

39. Pinkoski MJ, Hobman M, Heibein JA, Tomaselli K, Li F, Seth P, Froelich CJ, Bleackley RC (1998) Entry and trafficking of granzyme B in target cells during granzyme B-perforin-mediated apoptosis. Blood 92(3):1044-1054

40. Kuroda H, Mandai M, Konishi I, Yura Y, Tsuruta Y, Hamid AA, Nanbu K, Matsushita K, Mori T (1998) Human chorionic gonadotropin (hCG) inhibits cisplatin-induced apoptosis in ovarian cancer cells: possible role of up-regulation of insulin-like growth factor-1 by hCG. Int J Cancer 76(4):571-578

41. Kreitman RJ (1999) Immunotoxins in cancer therapy. Curr Opin Immunol 11(5):570-578

42. McGrath MS, Rosenblum MG, Philips MR, Scheinberg DA (2003) Immunotoxin resistance in multidrug resistant cells. Cancer Res 63(1):72-79 